\title{
Health Canada wants more funds from pharma
}

\author{
Cite as: CMAJ 2017 June 19;189:E845-6. doi: 10.1503/cmaj.1095439
}

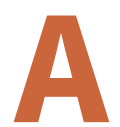
$\mathrm{n}$ amendment buried in the federal budget bill would pave the way for Health Canada to increase the fees it charges drug companies to cover more of the costs of regulating medicines. The proposed amendment to the Food and Drugs Act would empower the Minister of Health to set fees by ministerial order, rather than going through the more complicated process prescribed by the User Fees Act, which includes justifying any fee changes to parliament.

At a recent senate committee meeting, drug companies warned that the amendment will reduce oversight and transparency of Health Canada's fees, a point that also troubles health policy experts. But Health Canada told senators the current rules make it almost impossible to adjust fees in pace with the increasing costs of the drug review.

"Under the current approach, fees have only been updated once in 22 years," said Ed Morgan, director general of Policy, Planning and International Affairs at Health Canada's Health Products and Food Branch. That one update took 10 years to complete and by then "the fees were already out of date when they were implemented in 2011."

Despite a $2 \%$ annual increase, "the fees that Health Canada charges industry have been falling as a percentage of costs since 2011, and are now at about 40\%," he said. That's much less than the percentage of costs recovered by international peers, such as the United States Food and Drug Administration and the European Medicines Agency. "Other regulators routinely cover up to $100 \%$ of costs and are able to revise their fees in a business-like fashion, sometimes annually," Morgan explained.

Health Canada recovers about $\$ 99$ million a year from pharmaceutical companies, but it stands to recoup nearly $\$ 140$ million a year if fees are increased to cover $75 \%$ of the costs of regulating drugs. "We do intend to have discussions starting this summer about starting at a much higher percentage of the cost being recovered as opposed to a 50-50 deal," said Deryck Trehearne, director general of Resource Management and Operations at Health Canada. "There's a very demanding agenda in this government and the regulatory requirements are quite large. Anything we can do to take the temperature down is helpful."

\section{Transparency concerns}

Drug industry representatives opposed exempting Health Canada from the same transparency, oversight and accountability required of other departments. The current User Fees Act mandates industry consultation, parliamentary review of fee changes, and performance standards, among other conditions for collecting fees. The proposed amendment contains no such safeguards, "essentially exempt-

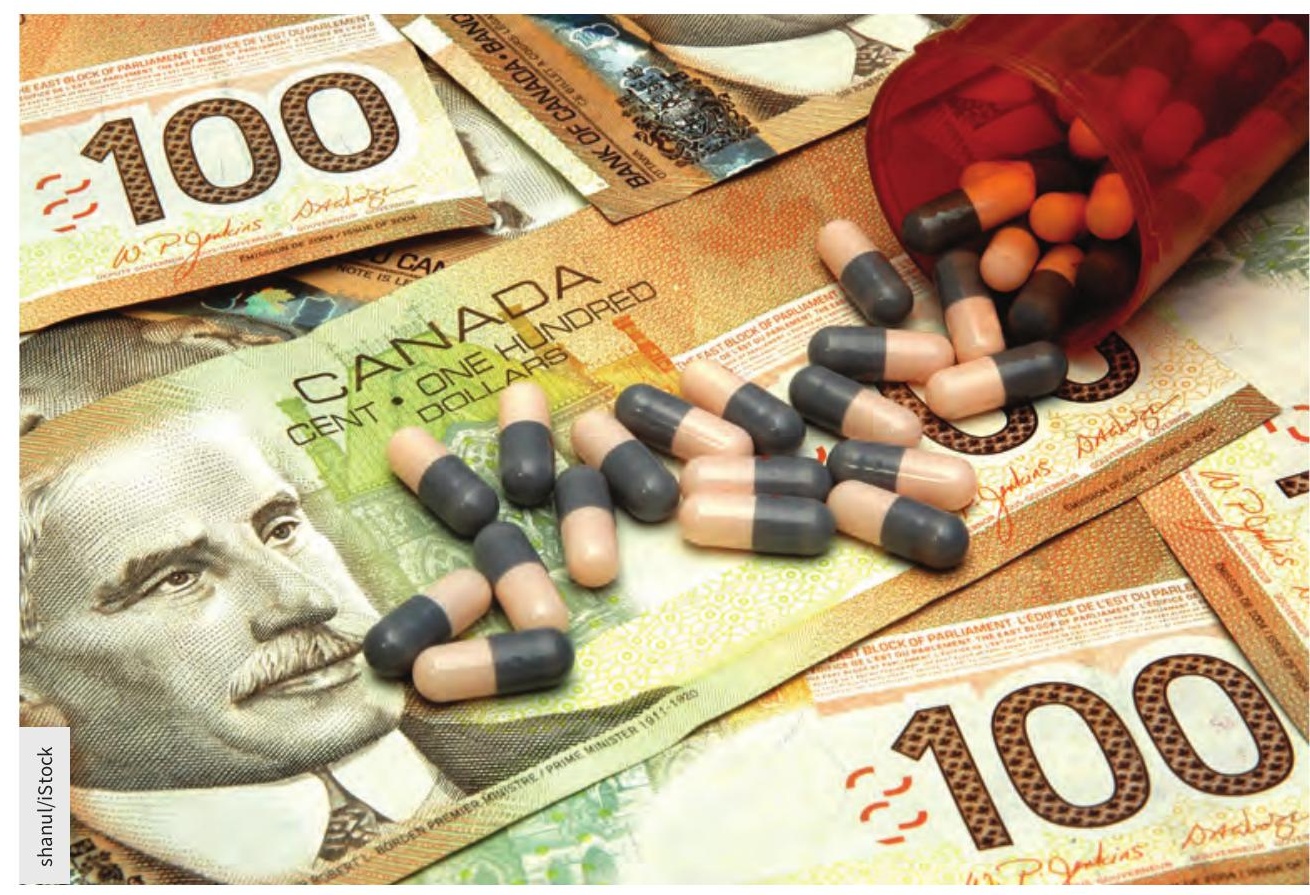

The senate is considering whether to give Health Canada more control over fees it charges drug companies.

The budget bill also proposes replacing the current cost-recovery rules with a modernized Service Fees Act, from which Health Canada would also be exempt. Morgan explained that the department can't wait years for a new act to come into force. Even the proposed amendment will take up to 15 months to implement, he said, and Health Canada is at the point of shuffling monies between programs to keep them afloat. ing Health Canada from meaningful parliamentary oversight," said Declan Hamill, vice-president of Legal, Regulatory Affairs and Policy at Innovative Medicines Canada, the association representing brandname drug companies.

Generic drug companies are particularly concerned by the amendment's silence on performance standards. Before these were introduced, up to $60 \%$ of generic drug submissions were in backlog, 
said Jim Keon, president of the Canadian Generic Pharmaceutical Association. "Health Canada review staff would first pick up a generic drug submission six months after it was received."

Health Canada only began dealing with the submissions in a timely way once fees became tied to meeting review deadlines, he said. "Without the prospect of severe penalties for missed performance targets, it's our view that generic drug submissions would never have been brought out of the backlog in the first place."

Conservative senators echoed the drug companies' concerns. "The lack of consultation clearly spelled out does worry me," said Senator Carolyn Stewart Olsen. Senator Paul McIntyre agreed. "There's obviously a decrease in consultation," as well as parliamentary oversight under the proposed amendment, he said.

Morgan assured senators that Health Canada will still "adhere to existing transparency and accountability measures," explaining that "implementation details will be articulated in regulations," if not law. However, it's not clear if these policies would be binding.

\section{Potential conflicts}

Health policy experts told CMAJ that parliamentary oversight of cost recovery is particularly important given the potential for conflicts of interest as Canada looks to increase its dependence on industry fees. "The more you get your money from a private source, the more you may consciously or unconsciously see yourself as being in service to that funding body," says Dr. Joel Lexchin, a professor of health policy at York University in Toronto.

Tying funding to performance standards further complicates the picture. "You've got a financial motivation for getting things done within a certain period of time, whether or not that time is adequate," Lexchin explains. The pressure to meet deadlines may compromise the drug review. For example, a 2008 study indicated that drugs approved within 60 days of the US deadline are five times more likely to be hit with a safety warning once they were on the market.

With strong safeguards, it's possible to collect user fees and still be a strict regulator, says Steve Morgan, professor of health policy at the University of British Columbia in Vancouver. However, he's skeptical of Health Canada's claim that it needs to increase the percentage of costs recovered. "Canada is not an outlier in terms of its fees relative to the size of its market, and we're neither high nor low compared to the international norm."
Yes, Health Canada may be "losing out on millions" in drug industry revenues, but government might view that as an opportunity to invest millions "if that's what it takes to maintain a level of independence," Morgan says.

The more important question is whether Canada has the necessary safeguards to protect the rigor of the drug review as it increases industry funding. "There are academics who feel strongly that cost recovery has come hand in hand with a reduction in regulatory rigor, and there may be truth to that," he says.

A recent federal audit revealed that less than $20 \%$ of Health Canada staff received mandatory ethics training, and many conflicts of interest declared by employees took too long to resolve.

The fact that industry is arguing that fee penalties ensure faster review times "means they actually perceive what researchers like Joel Lexchin and others fear, which is when you get more money from industry, they get their drugs to market faster," Morgan says. "It's that kind of language that's concerning, and that's the kind of thing that would need to be pushed back."

Lauren Vogel, CMAJ 